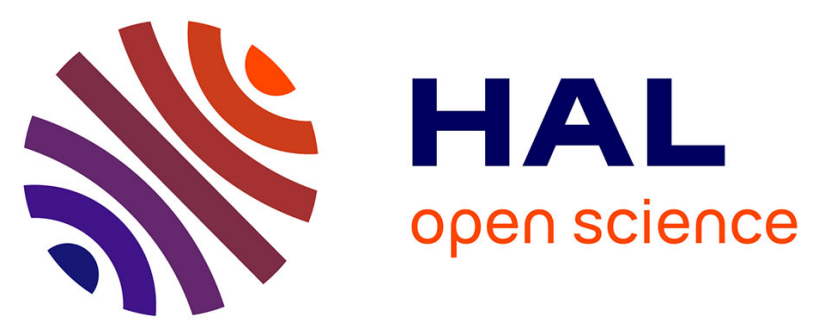

\title{
Does divergent selection predict the evolution of mate preference and reproductive isolation in the tropical butterfly genus Melinaea (Nymphalidae: Ithomiini)?
}

Melanie Mcclure, Louisa Mahrouche, Céline Houssin, Monica Monllor, Yann Le Poul, Brigitte B. Frerot, Alexandra Furtos, Marianne Elias

\section{To cite this version:}

Melanie Mcclure, Louisa Mahrouche, Céline Houssin, Monica Monllor, Yann Le Poul, et al.. Does divergent selection predict the evolution of mate preference and reproductive isolation in the tropical butterfly genus Melinaea (Nymphalidae: Ithomiini)?. Journal of Animal Ecology, 2019, 88 (6), pp.940952. 10.1111/1365-2656.12975 . mnhn-02165459

\section{HAL Id: mnhn-02165459}

https://hal-mnhn.archives-ouvertes.fr/mnhn-02165459

Submitted on 28 Jun 2019

HAL is a multi-disciplinary open access archive for the deposit and dissemination of scientific research documents, whether they are published or not. The documents may come from teaching and research institutions in France or abroad, or from public or private research centers.
L'archive ouverte pluridisciplinaire HAL, est destinée au dépôt et à la diffusion de documents scientifiques de niveau recherche, publiés ou non, émanant des établissements d'enseignement et de recherche français ou étrangers, des laboratoires publics ou privés. 
1 Does divergent selection predict the evolution of mate preference and reproductive isolation

2 in the tropical butterfly genus Melinaea (Nymphalidae: Ithomiini)?

3

4 McClure, M.*1, Mahrouche, L. ${ }^{2}$, Houssin, C. ${ }^{1}$, Monllor, M. ${ }^{1}$, Le Poul, Y. ${ }^{3}$, Frérot, B. ${ }^{4}$, Furtos, A. ${ }^{2}$, 5 Elias, $\mathrm{M}^{1}$

6

7 Institut Systématique Évolution Biodiversité (ISYEB), Centre National de la Recherche 8 Scientifique, MNHN, Sorbonne Université, EPHE, Paris, France

$9 \quad{ }^{2}$ Centre régional de spectrométrie de masse, Département de chimie, Université de Montréal, 10 Montréal, Canada

$11 \quad{ }^{3}$ Faculty of Biology, LMU Munich, Planegg-Martinsried, Germany

$12{ }^{4}$ Institut d'Écologie et des sciences de l'Environnement, IEES - INRA UMR 1392, Versailles

13 cedex, France

14 *Corresponding author. E-mail: mel_mcclure@hotmail.com

16 Abstract

17 1. Many studies have shown that speciation can be facilitated when a trait under divergent 18 selection also causes assortative mating. In Müllerian mimetic butterflies, a change in wing 19 colour pattern can cause reproductive isolation. However, colour pattern divergence does not 20 always lead to reproductive isolation. Understanding how divergent selection affects 21 speciation requires identifying the mechanisms that promote mate preference and/or 22 choosiness. 
23 2. This study addresses whether shifts in wing colour pattern drives mate preference and 24 reproductive isolation in the tropical butterfly genus Melinaea (Nymphalidae: Ithomiini), and 25 focuses on five taxa that form a speciation continuum, from subspecies to fully recognized 26 species.

27 3. Using genetic markers, wing colour pattern quantification, male pheromone characterization 28 and behavioural assays of mating preference, we characterize the extent of genetic and phenotypic differentiation between taxa and compare it to the level of reproductive isolation.

4. We show strong premating isolation between the closely related species $M$. satevis and $M$. marsaeus, in addition to genetic and phenotypic (colour pattern and pheromones) differentiation. By contrast, M. menophilus and M. marsaeus consist of pairs of subspecies that differ for colour pattern but that cannot be differentiated genetically. Pheromonal differentiation of subspecies was significant only for M. marsaeus, although most individuals were indistinguishable. Melinaea menophilus and M. marsaeus also differ in the strength of assortative mating, suggesting that mate preference has evolved only in M. marsaeus, consistent with selection against maladaptive offspring, as subspecific "hybrids" of $M$. marsaeus have intermediate, non-mimetic colour patterns, unlike those of $M$. menophilus which display either parental phenotypes.

5. We conclude that a shift in colour pattern per se is not sufficient for reproductive isolation, but rather, the evolution of assortative mating may be caused by selection against maladaptive intermediate phenotypes. This study suggests that mate preference and assortative mating evolve when adaptive, and that even in the early stages of divergence, reproductive isolation can be nearly complete due to mating preferences. 
46 Keywords: assortative mating, colour pattern, hybrids, mimicry, magic traits, reinforcement, 47 sexual selection, speciation

\section{Introduction}

A key aspect of evolutionary biology is determining the factors that promote population

51 diversification and the processes that initiate progress towards speciation. Divergence in both

52 mating preference and cues are expected to reduce mating between populations and increase

53 reproductive isolation (Boughman 2001), and many studies have highlighted the importance of

54 traits that are under divergent ecological selection that also contribute to assortative mating (e.g.

55 Jiggins et al. 2001; Servedio et al. 2011; Maan \& Seehausen 2012; Jiang, Bolnick \& Kirkpatrick

56 2013). Because the trait subject to divergent selection can directly lead to assortative mating, gene

57 flow is reduced, and these "magic traits" can be the first step in speciation (Servedio et al. 2011).

58 However, assortative mating requires the evolution of both divergent cues and preferences, and

59 divergence in one of these alone will not automatically lead to reproductive isolation (Maan \&

60 Seehausen 2012).

To understand how divergent selection affects reproductive isolation and hence speciation,

62 we need to identify the mechanisms that generate mating assortment. What is currently needed are

63 detailed studies of closely related taxa that span the speciation continuum, such as populations or

64 species pairs, that are under divergent ecological selection and that vary strongly in their degree of

65 reproductive isolation. A comparative approach based on natural replicates also offers a powerful

66 means with which to study the conditions conducive for speciation. Mimetic organisms, whereby

67 multiple co-occurring unpalatable species converge on the same warning signal and effectively

68 share the cost of educating predators, are especially well suited for studies on speciation, as species 
often consist of multiple subspecies diverging for adaptive traits such as wing colour pattern, which can then cause reproductive isolation through sexual and natural selection against phenotypic intermediates (Jiggins et al. 2001; Naisbit, Jiggins \& Mallet 2001; Merrill et al. 2012; Arias et al. 2016).

The tribe Ithomiini (ca. 390 species) represents the largest radiation of mimetic butterflies in the Neotropics, where they numerically dominate forest butterfly communities, and have been instrumental in the discovery and description of Müllerian and Batesian mimicry in the $19^{\text {th }}$ century (Bates 1862; Müller 1897). Indeed, the tribe is thought to drive mimicry in many Lepidoptera (Brown \& Benson 1974; Beccaloni 1997). However, due to the difficulty in breeding and maintaining ithomiines in captivity, no study has, until now, investigated mate choice and mating behaviour in this tribe. Here we present the first experimental test of reproductive isolation in the tribe Ithomiini, using the genus Melinaea.

The genus Melinaea consists of at least 14 species and over 70 subspecies (Lamas 2004; but see also McClure \& Elias 2017; McClure et al. 2018) distributed across much of the Neotropics and is oligophagous on the plant subfamily Solandreae (Solanaceae; Willmott \& Freitas 2006). A recent assessment of diversification rates in the tribe revealed that a clade of eight species in the genus experienced an extremely rapid and recent radiation (Chazot et al. 2017) in agreement with previous studies using mitochondrial and nuclear genes, and rapidly evolving microsatellite markers, that show little genetic differentiation among taxa of this clade (Whinnett et al. 2005; Elias et al. 2007; Dasmahapatra et al. 2010; McClure \& Elias 2017). The Melinaea of north-eastern Peru (San Martín and Loreto departments) are of particular interest for speciation studies, as multiple species, many consisting of different subspecies, are present and overlap in distribution. Different subspecies are characterised by different wing colour patterns which are associated with 
92 distinct mimetic communities, including with the polymorphic Heliconius numata, whose different

93 morphs are co-mimics to different Melinaea taxa (Brown \& Benson 1974; Beccaloni 1997). As a

94 result, distribution is often parapatric, with a different dominant taxon in each locality, and a 95 transition or contact zone where different taxa co-occur. Colour patterns are used in mate recognition in a range of mimetic organisms (Jiggins et al. 2001; Jiggins et al. 2006; Merrill et al.

97 2012), and this may also be the case in the genus Melinaea, although this has never before been investigated in Ithomiini. However, Jiggins et al. (2006) have demonstrated a phylogenetic pattern

99 of speciation that is correlated with changes in wing colour pattern in the genus Ithomia 100 (Ithomiini), which strongly suggests that this may be the case. In addition to colour pattern, 101 pheromones may also play an important role in mate recognition and reproductive isolation. 102 Indeed, Ithomiini male butterflies collect pyrrolizidine alkaloids (PA) which are thought to provide 103 toxicity and pheromone precursors (see Schulz et al. 2004 and references therein). Furthermore, 104 as in other ithomiines, male butterflies have hairpencils on their posterior wings that are modified 105 androconial scales used to diffuse these compounds (see e.g. Edgar, Culvenor \& Pliske 1975). 106 Premating isolation is expected to be especially strong since females appear to mate only once (i.e. 107 are monandrous; McClure \& Elias 2017). Indeed, mistakes or mating with subpar males likely 108 impose a high cost to females, and they are therefore expected to be choosy.

109 This paper focuses on five Melinaea taxa thought to form a speciation continuum, from 110 subspecies to fully recognized species (Lamas 2004): M. menophilus ssp. nov. 1 and M. men. 111 hicetas, M. marsaeus phasiana and M. mar. rileyi, and finally M. satevis cydon. Previous studies 112 have shown that these taxa utilize the same hostplant, Juanulloa parasitica (McClure \& Elias 113 2016; McClure \& Elias 2017). As such, McClure \& Elias (2016) suggested that diversification in 114 these taxa was likely driven by shifts in colour pattern linked to co-occurring Müllerian mimics 
115 and the resulting predation pressure rather than hostplant shifts. Using artificial models of the 116 polymorphic and Müllerian co-mimic Heliconius numata, Chouteau et al. (2016) and Arias et al.

117 (2016) have shown that migrants and intermediate phenotypes respectively, possess locally 118 unrecognized warning signals and suffer greater predator attack frequencies. As the Müllerian co119 mimics Heliconius numata and Melinaea are undistinguishable to predators (Llaurens, Joron \& 120 Théry 2014), the results of these studies can be extrapolated to the genus Melinaea. The main purpose of this study is to uncover the factors that drive reproductive isolation 122 (and therefore, speciation) between different mimetic taxa, and what, if anything, promotes the 123 evolution of mating preference and/or choosiness. Although most studies have focused on mating 124 cues (Servedio et al. 2011; Maan \& Seehausen 2012), determining the evolutionary consequences 125 of divergent selection on reproductive isolation requires studies of the variation that exist in both 126 mating cues and preferences in diverging taxa. The types of isolation that exist between partially 127 isolated taxa in nature are of great interest, as they can provide insight as to what mechanisms are 128 important in the early stages and which processes are then important in driving reproductive 129 isolation and speciation. Using genetic markers (microsatellites), wing colour pattern 130 quantification and vision models for butterflies and their avian predators, male pheromone 131 characterization and behavioural assays of mating preference, we characterize the extent of genetic 132 and phenotypic differentiation for five Melinaea taxa, and compare it to the level of mate 133 preference (as a measure of premating isolation). We then discuss the factors that best explain 134 differential progress towards speciation in light of our results. 
137 Butterfly sampling. Butterflies were collected in north-eastern Peru from 2011 to 2016. 138 Collection localities consisted of premontane forest habitats near Tarapoto (Rio Shilcayo basin:

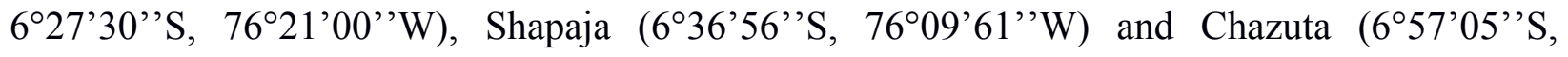

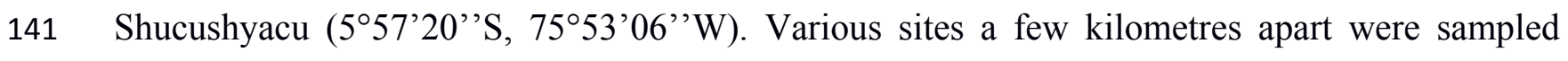
142 within each locality. The number of individuals of each taxon used to measure genetic 143 differentiation, pheromone characterization and colour pattern quantification are found in Table 1.

145 rileyi were considered to be putative hybrids. To test if the occurrence of putative hybrids deviated 146 from expectations if mating were random, a Pearson's $\chi^{2}$ test was done on the observed frequencies 147 obtained from the data and by calculating expected frequencies based on Hardy-Weinberg 148 equilibrium (Table S1). This was done both for the entire distribution (i.e. all localities were 149 pooled) and for the contact zone, where hybridization may be more common.

Rearing conditions. Gravid wild caught females were kept in $2 \times 2 \times 2 \mathrm{~m}$ outdoor insectaries under 152 ambient conditions in Tarapoto, San Martín, where all rearing was carried out (see McClure \& 153 Elias 2016 for further information). Butterflies were provided with nourishment in the form of 154 sugar water solution and bee pollen. All species in this study use J. parasitica as a host plant 155 (McClure \& Elias 2016; McClure \& Elias 2017), and as such, potted J. parasitica plants were used 156 for oviposition, and larvae collected in the cages were reared individually in transparent plastic 157 containers in the shade behind a nearby building under ambient conditions. Larvae were checked 158 daily for food replacement and cleaning, and leaves were offered ad libitum. 
Newly emerged butterflies were kept segregated by sex in outdoor insectaries until use, with sugar water solution and bee pollen for nourishment, and pyrrolizidine alkaloid sources in the form of withered Heliotropium sp. (Boraginaceae) and Eupatorieae (Asteraceae).

No-choice mating experiments. To test for reproductive isolation, no-choice experiments were used as they examine whether mating can occur, when no alternatives are present (a situation more likely to reflect what happens in nature). Strict preference in a choice situation does not preclude the possibility of accepting a mate when no alternative is present. Trials were carried out with four males and four females, unrelated, and of either the same or different taxa. Trials lasted for four days or until a mating event occurred and 12 replicates were done for each combination. For trials between different taxa, half of the replicates were done using each reciprocal cross so as to control for potentially different mating probabilities. For trials between the closely related species $M$. satevis cydon and M. marsaeus, half of the replicates were done using each of the $M$. marsaeus subspecies. However, the results of these reciprocal crosses were not found to be statistically different $\left(M\right.$. menophilus: $\chi^{2}=1.2, \mathrm{df}=1, p=0.273 ;$ M. marsaeus: no mating was observed; $M$. marsaeus x M. satevis cydon: no mating was observed; see Table 2), and were therefore pooled. Melinaea marsaeus was used with $M$. satevis cydon to test assortative mating between closely related species as McClure \& Elias (2017) have shown, using microsatellite markers, that $M$. menophilus clusters separately from M. marsaeus and M. satevis cydon. The latter two species are therefore more closely related, and provide a relevant comparison after reproductive isolation is complete.

McClure \& Elias (2017) reported that copula lasted anywhere between a little over an hour up to $24 \mathrm{~h}$. As such, cages were checked hourly between 6 AM and 6 PM (hours during which 
182 there is daylight) every day for mating events. To further ensure that no mating events took place

183

184 185

unnoticed, the presence of a spermatophore was ascertained by palping the females' abdomen at the end of the experiment. Males, regardless of whether they were mated, and females that did not mate, were occasionally re-used, but only after 7-10 days had elapsed to prevent habituation and no more than once. Females that mated were not re-used.

Mating probabilities $P_{i j}$ between $i$-type females and $j$-type males relative to the probability of mating within types were estimated using likelihood in order to test between hypotheses (McMillan, Jiggins \& Mallet 1997; Naisbit, Jiggins \& Mallet 2001). The probability of mating occurring can be calculated by maximizing the $\log _{\mathrm{e}}$-likelihood expression:

$\mathrm{L}\left(P_{i j}\right)=m_{i j} \log _{\mathrm{e}}\left(P_{i j}\right)+\left(N_{i j}-m_{i j}\right) \log _{\mathrm{e}}\left(1-P_{i j}\right)$

$\mathrm{N}$ and $\mathrm{m}$ are the total number of trials and the number of trials where mating occurred, respectively. Fitting models with different numbers of parameters (i.e., same versus different mating probabilities for different types of crosses) enabled to test for differences in the mating probability across trials using a likelihood ratio test with $\mathrm{G}=2 \Delta \log _{\mathrm{e}} \mathrm{L}$, which asymptotically follows a $\chi 2$ distribution (Edwards 1972). As such, we were able to test whether individuals of different taxa mate less frequently than those of the same taxon, or if all crosses are either equal or all significantly different from one another.

An index of premating isolation similar to what was used by Coyne \& Orr (1989) was also calculated using the expression:

$$
1-\frac{\text { frequencyofheterospecificmating }}{\text { frequencyof conspecificmating }}
$$

This index ranges from $-\infty$ (complete disassortative mating) through 0 (no mating isolation) to 1 (complete mating isolation). 
Genetic differentiation. Samples used in this study were preserved in either ethanol or in saltsaturated 20\% dimethylsulphoxide (DMSO) with ethylenediaminetetraacetic acid (EDTA). Individuals were genotyped at 12 microsatellite markers developed for Melinaea, using primers and PCR conditions from McClure et al. (2014). The extent of genetic differentiation and admixture, and the number of possible genetic clusters (or distinct groups), was assessed in three ways. First, STRUCTURE version 2.3.4 (Pritchard, Stevens \& Donnelly 2000) was used on the data, run with 500000 updates of the Markov chain after an initial 'burn-in' of 50000 updates for one to five genetic clusters $(K=1-5)$, with five replicates at each value of $K$. The method described by Evanno et al. (2005), based on the second-order rate of change of the log likelihood and implemented in STRUCTURE HARVESTER (Earl \& vonHoldt 2012), was used to determine the number of clusters that best describe the data. A factorial correspondence analysis was also used on the data using GENETIX (Belkhir et al. 1996). Finally, Fst values for each pair of taxa were calculated using GENEPOP version 4.2 (Raymond \& Rousset 1995).

Differentiation of colour pattern. Differentiation in colour pattern was quantified using Colour Pattern Modelling (CPM) described by Le Poul et al. (2014). Photographs, taken under standardized conditions (see Le Poul et al. 2014 for details), of the dorsal and ventral sides of forewings and hindwings of each specimen were used. The CPM automatically detects and eliminates the background in the pictures and each pixel of the butterfly wing image is automatically attributed a colour, which is then categorized into one of three major colours present in the wing patterns (that is, black, orange or yellow). Hind and forewings are aligned separately using a rigid transformation, and similarity (accounting both for wing shape and pattern) with a wing model that averages all wing images is maximized recursively. After alignment, the position 
228 of each pixel in the wing image is considered homologous among all individuals, enabling a pixelby-pixel analysis of pattern variation.

In order to link divergence in colour pattern to reproductive isolation (specifically,

231 prezygotic isolation driven by mate choice, and postzygotic isolation driven by predation), the

232 value of each pixel was re-calculated by incorporating models of animal vision (see Arias et al.

2332016 for details) and by using the precise colour spectrum of each colour (see Llaurens, Joron \&

234 Théry 2014). Models of animal vision, based on the sensitivities of photoreceptors present in their

235 eyes, allow inferences about the colour contrasts and the conspicuousness of the different colours

236 that can be perceived by different animals. As such, two avian vision systems that vary in their

237 sensitivity to ultra-violets (i.e. wavelengths below 400nm) and one butterfly vision system were

238 performed. All vision systems consist of four photoreceptors. Specifically, the quantum catches,

239 which is the relative amount of light captured by each photoreceptor when observing a given colour

240 (Iriel \& Lagorio 2010), was applied using the method described in Vorobyev \& Osorio (1998) and

241 assuming a Weber fraction of 0.05 for all vision systems. A light environment corresponding to

242 both small and large gaps in a forest canopy (computed as in Llaurens, Joron \& Théry 2014) was

243 used. As the photoreceptor sensitivities of the birds composing the predator community in this

244 study system are not known, the calculations were based on the two main vision systems found in

245 birds. The blue tit (Parus caeruleus) was used for vision with ultra-violet sensitive pigments

246 (UVS), with cone proportion and sensitivity as described by Hart et al. (2000), and the shearwater

247 (Puffinus pacificus) was used for vision with violet sensitive pigments (VS), as described by Hart

248 (2004). To model butterfly vision, the photoreceptors sensitivity was computed using the visual

249 sensitivity peaks reported for Danaus plexippus (the monarch, the closest relative of Melinaea for

250 which sensitivity peaks are known) in Stalleicken, Labhart \& Mouritsen (2006) and Blackiston, 
251 Briscoe \& Weiss (2011), applying Stavenga (2010)'s equations. Since Blackiston, Briscoe \& 252 Weiss (2011) reported the existence of a dark orange filter in the long wavelength receptor, which 253 effectively gives rise to a fourth type of receptor, we also modelled this filtered photoreceptor by 254 digitizing the spectrum reported in McCulloch, Osorio \& Briscoe (2016) for Heliconius erato (the 255 closest butterfly species - also a Nymphalidae - for which the spectrum has been characterized, 256 and whose long wavelength photoreceptor peaks at the same value as D. plexippus) using the 257 software Graph Grabber 2.0 (www.quintessa.org/). The vision model for D. plexippus is available 258 in ESM. The precise colour spectrum of each colour detected by CPM (black, orange and yellow) 259 were those taken on Melinaea by Llaurens, Joron \& Théry (2014). Quantum catches for each 260 photoreceptor in birds and butterflies were estimated using AVICOL (Gomez 2006), under large 261 light gap and small light gap light conditions. The phenotypic variation (variation among all pixels 262 common between all wings) after accounting for animal vision was summarized using a principle 263 component analysis (PCA). Differences between groups were tested using ADONIS 264 (PERMANOVA) in the R package Vegan (Oksanen et al. 2016), followed by a pairwise 265 comparison (i.e. post hoc test) with Bonferroni correction (pairwiseAdonis: Martinez Arbizu 266 2017). Finally, differentiation between taxa was measured as Euclidean distances between 267 centroids in PCA space.

269 Chemical analysis. Preliminary tests of female wing extracts failed to reveal any compounds, so 270 all further tests focused on males. The hairpencils (i.e. androconial scales) of 6-10 males per taxa 271 were dissected and extracted individually in $100 \mu$ of ultrapure dichloromethane (Sigma272 Aldrich () shortly after capture. Samples were kept at $-20^{\circ} \mathrm{C}$ until analysis in Montreal, Canada, 273 by gas chromatography/mass spectrometry (GC/MS) with an Agilent 7890A-5975C. Using pulsed 
274 splitless injection, $2 \mu \mathrm{L}$ of each extract was injected on an Agilent HP-5MS column (30 m x 250

$275 \mu \mathrm{m} \times 0.25 \mu \mathrm{m}$ ) with the inlet maintained at $250^{\circ} \mathrm{C}$. Helium was used as a carrier gas and flow rate

276 was of $1.5411 \mathrm{~mL} / \mathrm{min}$. Temperature gradient was programmed from $50^{\circ} \mathrm{C}$ to $300^{\circ} \mathrm{C}$ at a rate of

$2778^{\circ} \mathrm{C} / \mathrm{min}$ for a total run time of 39 min. Kovats' retention indices (RIs) were computed using $\mathrm{n}$ -

278 alkanes from $\mathrm{C} 8$ to $\mathrm{C} 20$ that were eluted under the same conditions as the samples (external

279 standards). Compounds were identified by comparison of mass spectra and gas chromatographic

280 retention indices to those in the literature and the NIST library. A data matrix of all the compounds

281 for each individual was aligned using GCAligner 1.0 (Dellicour \& Lecocq 2013). Relative

282 concentrations were determined by peak area analysis and differences between groups were

283 visualized using nonmetric multidimensional scaling (NMDS) ordination based on Bray-Curtis

284 similarity matrix, using the function metaMDS in the R package Vegan (Oksanen et al. 2016).

285 Differences between groups were tested using ADONIS (PERMANOVA) in the R package Vegan,

286 followed by a pairwise comparison (i.e. Post hoc test) with Bonferroni correction (pairwiseAdonis:

287 Martinez Arbizu 2017). If differences within species (i.e. between subspecies) were found to be

288 significant, this was followed with a non-parametric Mann-Whitney $U$ test so as to test for

289 differences in the amount of each compound. Finally, differentiation between taxa was measured 290 as Euclidean distances between centroids.

291

292 Results

293 Distribution. Partial geographical isolation is observed between the subspecies of both $M$. 294 marsaeus and M. menophilus, with uneven abundance at the different localities. Distribution and 295 relative frequency of the five different taxa in each region is shown in Fig. S1. The general pattern 296 of distribution for these subspecies pairs consists in one subspecies being present in premontane 
297 forest (M. men. ssp. nov. 1 and M. mar. phasiana) and the other in lowland forest (M. men. hicetas 298 and M. mar. rileyi). The different subspecies are considered parapatric, and both species have a 299 transition or contact zone in the lowlands near Pongo, a known suture and hybrid zone (Whinnett 300 et al. 2005; Dasmahapatra et al. 2010). Finally, the third species, M. satevis cydon, is a lowland 301 species.

Overall, the number of potential M. marsaeus hybrids (based on intermediate phenotypes) 303 is much lower than expected under random mating ( $4.4 \%$ observed vs. $45.8 \%$ expected; see Table $304 \mathrm{~S} 1)$. This is also true in the contact zone where a strong hybrid deficit is observed (12.5\% observed 305 vs. $42.97 \%$ expected; see Table S1). Of 34 phenotypically "pure" females that were collected in 306 the field and used to produce broods, two produced offspring of intermediate "hybrid" phenotypes 307 (i.e. $5.9 \%$ of females). This is putatively the result of mating between M. mar. phasiana and M. 308 mar. rileyi.

No putative M. menophilus hybrids were observed. This is consistent with McClure \& Elias 310 (2017) who reported that progeny of crosses between M. men. hicetas and M. men. ssp. nov. 1 311 possess either of the parental phenotypes.

No-choice mating experiments. Mating events were much more prevalent within taxa for both 314 the closely related species $M$. satevis cydon and M. marsaeus $(p<0.01)$, and within the $M$. marsaeus subspecies $(p<0.01)$. However, this was not true for M. menophilus $(p>0.05)$. Table 2 316 shows mating probabilities both within and between subspecies, and between closely related 317 species. Both the closely related species M. marsaeus and M. satevis cydon showed strong 318 premating isolation, as did the $M$. marsaeus subspecies (index of premating isolation=1). By 
contrast, the subspecies of $M$. menophilus showed no assortative mating (index of premating isolation $=0$ ).

Genetic differentiation. Both STRUCTURE (Fig. S2) and the factorial correspondence analyses (GENETIX; Fig. 1) detected low levels of structuring $(\mathrm{K}=3$; Delta $\mathrm{K}$ peak=7.5), with the three groups corresponding to the three species (M. menophilus, M. marsaeus and M. satevis cydon). Subspecies clustered together and presented high levels of admixture, as also evidenced by low Fst values (Fst within M. menophilus $=0.01$ and $M$. marsaeus $<0.01$; Table 3 ). The species $M$. marsaeus and $M$. satevis cydon were also found to be closely related (Fst $=0.02-0.04$; Table 3 ).

Differentiation of colour pattern. Fig. S3 shows the average wing colour patterns, calculated by the CPM, for each Melinaea taxon (Fig. S3a) and the heatmaps (Fig. S3b) generated to visualize how each of the three colours (black, orange and yellow) vary (from blue to red) across the wings. Because results were identical for animal visions under both light conditions (large and small light gaps), only models based on small light gaps, which likely replicate conditions in primary forest where natural populations of Melinaea occur, are shown. Similarly, results for both avian vision (VS and UVS vision) were the same, and as such, only results for UVS vision (i.e. the blue tit) are discussed here, although results for VS vision are shown in Fig. S4.

Differentiation in colour pattern was significant for all taxa and putative hybrids, both under butterfly (PERMANOVA ADONIS: $\mathrm{F}=79.39$; $\mathrm{df}=5 ; p=0.001$; Fig. 2a) and avian (PERMANOVA ADONIS: $\mathrm{F}=73.30 ; \mathrm{df}=5 ; p=0.001$; Fig. $2 \mathrm{~b}$ ) vision. A pairwise post hoc test with Bonferroni correction shows all groups as being significantly different from each other $(p=$ 0.001). However, differentiation of the two subspecies of $M$. menophilus, which differ for a single 
342 yellow band, appears greater under the butterfly vision model than under the avian vision model.

343 Euclidean distances between centroids of pairs of taxa are presented in Table 3.

345 Chemical analysis. A total of six compounds (Table 4) were identified, four of which were 346 common to all taxa, albeit at different ratios (Fig. 3), and two were unique to M. menophilus. A 347 comparison of the different chemical extracts was found to be significantly different 348 (PERMANOVA ADONIS: $\mathrm{F}=27.60 ; \mathrm{df}=4 ; p=0.001$ ) and the NMDS ordinal plot shows the three 349 species as being completely separate, but the subspecies as clustering together (Fig. 4). A pairwise 350 post hoc test with Bonferroni correction confirmed that the closely related species $M$. marsaeus 351 and $M$. satevis cydon are significantly different from each other $(p=0.015)$. The subspecies of $M$. 352 menophilus $(p=1.0$ ) were not found to be significantly different, but the subspecies of $M$. 353 marsaeus were $(p=0.02)$. This difference appears to be the result of a difference in the ratio 354 between the $\Delta \mathrm{C} 21$ acid $(\mathrm{U}=7 ; p=0.002)$ and the $\mathrm{C} 21$ acid $(\mathrm{U}=4 ; p<0.01 ;$ Fig. 3). However, 355 most individuals of both subspecies, in addition to the potential hybrid, possess the same 356 intermediate ratio of the two compounds (Figs $3 \& 4$ ). Euclidean distances between centroids of

357 pairs of taxa are presented in Table 3 and show increasing levels of differentiation with increasing 358 reproductive isolation.

\section{Discussion}

361 Synchrony between assortative mating and divergent selection can trigger rapid speciation. Indeed, when mate choice is based on an ecologically important trait, divergence in that trait can facilitate reproductive isolation and speciation, even with gene flow (Servedio et al. 2011; Kopp et al. 2018 364 and references therein). Mimicry is a good example of a trait under strong ecological divergent 
365 selection that can also be used as a mating cue, and this has been shown for many different 366 organisms, including fish (Hypoplectrus coral reef fishes: Puebla et al. 2007), frogs (Dendrobates:

367 Reynolds \& Fitzpatrick 2007) and butterflies (Heliconius: Jiggins et al. 2001; Merrill et al. 2012).

368 Because the evolution of mate choice is thought to be an important process generating and 369 maintaining biological diversity, determining which traits and corresponding selective pressures 370 initiate differentiation is important, but understanding the causes of speciation also requires studies 371 associated with diverging preference and/or increased choosiness (Maan \& Seehausen 2012). In 372 the poison frog Ranitomeya imitator, Twomey et al. (2016) found that although colour pattern 373 diverges repeatedly, genome-wide divergence occurs only when there is mate preference, resulting 374 in assortative mating. Similarly, in the mimetic Heliconius butterflies, Chouteau et al. (2017) 375 showed that $H$. numata is a panmictic population despite the presence of polymorphism as a result 376 of disassortative mating, an unusual feature in Müllerian mimetic organisms.

377 To understand how divergent selection affects speciation, we need to know how it affects 378 the evolution of reproductive isolation. Servedio \& Boughman (2017) suggested that the ideal 379 empirical evidence to evaluate how the evolution of choosiness affects speciation would result 380 from testing whether evolutionary changes in choosiness are associated with changes in assortative 381 mating among species and reduction in gene flow, preferably by comparing early to late stages of 382 speciation. The genus Melinaea is therefore especially pertinent in furthering our understanding 383 of the evolution of reproductive isolation and speciation as the genus has undergone a rapid and 384 recent diversification, and consists of pairs of taxa that differ in their degree of differentiation and 385 assortative mating, with some in the very early stages of speciation.

Our results show strong premating isolation between the closely related species $M$. satevis 387 cydon and M. marsaeus, in addition to genetic and phenotypic differentiation, both for the colour 
pattern and pheromones. This is consistent with McClure \& Elias (2017) who observed that mating between sympatric species were extremely rare, including between these two closely related species, and that these crosses never produced any eggs. Reproductive isolation may not be as strong between allopatric species, however, and McClure et al. (2018) reported having successfully crossed the allopatric species $M$. satevis cydon and M. tarapotensis (formerly M. satevis tarapotensis: see McClure et al. 2018). These crosses successfully produced viable hybrid offspring, and although most of the gametes of these hybrids had an unbalanced genome and a degenerative appearance, some hybrids produced a small proportion (4\%) of viable offspring in backcrosses (McClure et al. 2018). In regards to the sympatric species M. satevis cydon and $M$. marsaeus, strong pre- and post-mating isolation may prevent the costly production of hybrids with possible genetic incompatibilities.

Premating isolation was also observed between the subspecies of M. marsaeus, but not those of M. menophilus, despite the absence of genetic differentiation between subspecies of both these species. McClure and Elias (2017) observed mating pairs of M. menophilus, and reported that these crosses were fertile and resulted in viable progeny. Chemical differentiation was not significantly different between the subspecies of $M$. menophilus, but was significantly different between the subspecies of M. marsaeus. This difference appears to be driven by a difference in the ratio between the $\Delta \mathrm{C} 21$ acid and the $\mathrm{C} 21$ acid. However, whether this difference can be perceived by the butterflies and whether it is biologically significant remains unknown. Furthermore, this difference was not present in all individuals, with many individuals of both subspecies and the potential hybrid possessing the same ratio. This suggests that even if this difference is biologically significant, it is not the sole trait used for mate recognition. As such, colour pattern is likely the 
410 first trait to diversify and be used in mate recognition. Chemical differentiation may only occur 411 subsequently, reinforcing mate recognition and premating isolation.

Differentiation of colour pattern was significantly different between subspecies of both 413 species, but this differentiation was found to be more pronounced between the subspecies of $M$.

414 marsaeus. This was especially true when differentiation was modelled on bird vision, thought to 415 be the main predators. A study by Llaurens et al. (2014) that compared the colour pattern of 416 Heliconius numata with that of their Müllerian co-mimics Melinaea found that the colour contrast 417 of yellow against a black background was greater for butterflies than for birds. The authors 418 suggested that this variation in colour, likely undetectable to birds, might be used by butterflies to 419 distinguish between mating partners without losing the benefits of mimicry. As such, migrants 420 between populations of $M$. marsaeus are likely to suffer higher levels of predator attacks because 421 they are strongly non-mimetic outside their habitat (Chouteau, Arias \& Joron 2016), which can 422 directly reduce gene flow between populations by lowering the rate of heterospecific encounters. 423 Differences in the distribution of the two species may also be due to differences in the strength of 424 disruptive selection in the form of predation. In M. menophilus, where both phenotypes differ in 425 the presence or absence of a single yellow band, the overlap in distribution is wide and both 426 phenotypes occur to some extent throughout their range. In M. marsaeus, where both phenotypes 427 differ more considerably, area of contact is narrow and each phenotype is almost exclusively 428 present at either end of the distribution.

429 Furthermore, putative hybrids between M. mar. phasiana and M. mar. rileyi possess 430 intermediate non-mimetic colour patterns and likely suffer intense frequency-dependent predation 431 similar to what is observed in the perfect co-mimic Heliconius numata (Arias et al. 2016), which 432 can further decrease gene flow and drive the spread of alleles for enhanced mate preference and/or 
433 choosiness in a reinforcement-like process. In Heliconius butterflies, Merrill et al. (2012)

434 suggested that selection against hybrids was as strong as selection against migrants (in this case, a

435 non-mimetic control species). Progeny of crosses between M. men. hicetas and M. men. ssp. nov.

4361 do not produce phenotypic intermediates, but rather possess either of the parental phenotypes,

437 with the hicetas phenotype appearing to be at least partly dominant (McClure \& Elias 2017).

438 Although currently untested, differences in colour pattern within M. menophilus may be the result

439 of a single locus with dominance, and this genetic architecture may differ from other Melinaea

440 species, including M. marsaeus. Nevertheless, as there are no intermediate phenotypes produced

441 in M. menophilus, selective pressure against mating between taxa is likely reduced and rampant

442 gene flow can be expected, thereby inhibiting the fixation of preference or increased choosiness

443 alleles. Yukilevich (2012) demonstrated that, in Drosophila, asymmetries in the strength of

444 premating isolation between species pairs matches the cost of producing hybrids. As such, at least

445 in M. marsaeus, mating preference may have directly evolved in response to selection against

446 maladaptive offspring of intermediate phenotypes.

447 In this study we show that the absence of ecological adaptations other than colour pattern

448 (see McClure \& Elias 2016) does not preclude the evolution of mating isolation. In fact, through

449 the maintenance of a spatial mosaic of mimetic colour patterns, predation on Müllerian mimics

450 constrains geographical distribution and allows for different species or subspecies, even those with

451 similar ecological niches, to exist in different regions (Aubier, Joron \& Sherratt 2017). This study

452 also suggests that mate preference and assortative mating evolve adaptively in response to

453 divergent selection, and that even in the early stages of speciation, reproductive isolation can be

454 nearly complete due to mating preferences, as seen in M. marsaeus. But perhaps surprisingly, we

455 also show that changes in traits used for mate recognition, such as colour pattern, does not 
456 invariably lead to reproductive isolation, as demonstrated by the equal hetero- and conspecific

457 mating probabilities observed in M. menophilus. Nevertheless, populations of M. menophilus

458 remain partly segregated by colour pattern, likely as a result of selection against immigrants.

459 Mallet \& Barton (1989) showed selection against immigrants across a hybrid zone to be of 52\%

460 where two races of $H$. erato meet, sufficient to maintain a cline in colour pattern, despite random

461 mating. But because M. menophilus does not produce any phenotypic hybrids, it is presently

462 difficult to evaluate the true occurrence of heterospecific mating in the field.

463 In conclusion, we find that premating isolation in Melinaea arises early and quickly, with

464 apparently no intermediate levels of premating isolation, despite a continuum of genetic and

465 phenotypic differentiation. Our results suggest that colour patterns adapted to different mimicry

466 rings may be used in mate recognition. However, reproductive isolation, as a result of mate

467 preference and/or increased choosiness, and variable progress towards speciation is consistent with

468 selection against maladaptive hybrids rather than a change in colour pattern per se. Uncovering the

469 evolutionary cause of assortative mating requires the comparative analyses of the strength of

470 assortative mating across different taxa subject to different selective pressures or genetic

471 architectures (Jiang, Bolnick \& Kirkpatrick 2013). The exceptional conditions present in the region

472 of Tarapoto, north-eastern Peru, where multiple species form concordant contact or hybrid zones

473 between taxa of lowland and premontane forests (Dasmahapatra et al. 2010) offer an optimal

474 natural setting to investigate the evolution of assortative mating across a large range of taxa.

475

476 Authors' contributions. MMc and ME designed and coordinated the study. MMc collected the

477 samples and field data, performed the experiments, carried out the molecular lab work, analysed

478 the molecular, chemical and experimental data and drafted the manuscript. LM and AF analysed 
479 the chemical extracts, and BF identified the chemical compounds. ME performed butterfly vision 480 modelling and $\mathrm{CH}, \mathrm{MMo}, \mathrm{YLP}$ and ME analysed the colour pattern of the wings. ME obtained the 481 funding and helped draft the manuscript. All authors gave final approval for publication.

482

483

Data accessibility. Data available from the Dryad Digital Repository:

484 https://doi.org/10.5061/dryad.008b59c (McClure et al. 2019)

485

486 Funding. This research was funded by a CNRS ATIP grant and ANR grant (SPECREP) awarded

487 to ME and by the Fonds Québecois de la Recherche sur la Nature et les Technologies (FQRNT) 488 as a PDF award to MMc.

489

490

Acknowledgements. We thank the Peruvian authorities and Dr Gerardo Lamas (Museo de

491 Historia Natural, Universidad Mayor de San Marcos) for research permits (236-2012-AG-DGFFS-

492 DGEFFS, 201-2013-MINA-GRI-DGFFS/DGEFFS and 002-2015-SERFOR-DGGSPFFS). We

493 also thank Mario Tuanama, Ronald Mori-Pezo and Javier Bacigalupo for their precious help in the

494 field. Molecular work was carried out at the Service de Systématique Moléculaire du Muséum

495 National d'Histoire Naturelle (CNRS-UMR 2700). We thank Violaine Llaurens, Doris Gomez and

496 Monica Arias for providing spectra for Melinaea taxa, ambient light files and quantum catches for

497 birds to perform the vision modelling. We thank Doris Gomez and Adriana Briscoe for advice on

498 butterfly vision modelling. 


\section{References}

Arias, M., le Poul, Y., Chouteau, M., Boisseau, R., Rosser, N., Théry, M. \& Llaurens, V. (2016). Crossing fitness valleys: empirical estimation of a fitness landscape associated with polymorphic mimicry. Proceedings of the Royal Society of London, Series B: Biological Sciences, 283, DOI: 10.1098/rspb.2016.0391.

Aubier, T., Joron, M. \& Sherratt, T.N. (2017). Mimicry among unequally defended prey should be mutualistic when predators sample optimally. American Naturalist, 189, 267-282.

Bates, H. (1862). Contributions to an insect fauna of the Amazon valley: Lepidoptera: Heliconidae. Transactions of the Linnean Society of London, 25, 495-566.

Beccaloni, G. (1997). Ecology, natural history and behaviour of ithomiine butterflies and their mimics in Ecuador (Lepidoptera: Nymphalidae: Ithomiinae). Tropical Lepidoptera, 8, 103124.

Belkhir, K., Borsa, P., Chikhi, L., Raufaste, N. \& Bonhomme, F. (1996). GENETIX 4.0.4, Logiciel sous Windows TM pour la génétique des populations. Laboratoire Génome, Populations, Interactions, CNRS UMR 5000, Université de Montpellier II, Montpellier, France, (http://www.univ-montp2.fr/ genetix/genetix/constr.htm\#download).

Blackiston, D., Briscoe, A. \& Weiss, M. (2011). Color vision and learning in the monarch butterfly, Danaus plexippus (Nymphalidae). The Journal of Experimental Biology, 214, 509-520.

Boughman, J. (2001). Divergent sexual selection enhances reproductive isolation in sticklebacks. Nature, 411, 944-948.

Brown, K.J. \& Benson, W. (1974). Adaptive polymorphism associated with multiple Müllerian mimicry in Heliconius numata (Lepid. Nymph.). Biotropica, 6, 205-228. 
521 Chazot, N., Willmott, K., Lamas, G., Freitas, A., Piron-Prunier, F., Arias, C., Mallet, J., De-Silva,

522

523

524

525

526

527

528

529

530

531

532

533

534

535

536

537

538

539

540

541

D. \& Elias, M. (2017). Renewed diversification following Miocene landscape turnover in a Neotropical butterfly radiation. BioRxiv https://doi.org/10.1101/148189, Reviewed \& recommended

by

PCI

Evolutionary

Biology (http://dx.doi.org/10.24072/pci.evolbiol.100032).

Chouteau, M., Arias, M. \& Joron, M. (2016). Warning signals are under positive frequencydependent selection in nature. Proceedings of the National Academy of Sciences of the United States of America, 113, 2164-2169.

Chouteau, M., Llaurens, V., Piron-Prunier, F. \& Joron, M. (2017). Polymorphism at a mimicry supergene maintained by opposing frequency-dependent selection pressures. Proceedings of the National Academy of Sciences of the United States of America, 114, 8325-8329.

Coyne, J. \& Orr, H. (1989). Patterns of speciation in Drosophila. Evolution, 43, 362-381.

Dasmahapatra, K.K., Lamas, G., Simpson, F. \& Mallet, J. (2010). The anatomy of a "suture zone" in Amazonian butterflies: a coalescent-based test for vicariant geographic divergence and speciation. Molecular Ecology, 19, 4283-4301.

Dellicour, S. \& Lecocq, T. (2013). GCALIGNER 1.0: an alignment program to compute a multiple sample comparison data matrix from large eco-chemical datasets obtained by GC. Journal of Separation Science, 36, 3206-3209.

Earl, D. \& vonHoldt, B. (2012). STRUCTURE HARVESTER: a website and program for visualizing STRUCTURE output and implementing the Evanno method. Conservation Genetics Resources, 4, 359-361. 
542 Edgar, J., Culvenor, C. \& Pliske, T. (1975). Isolation of a lactone, structurally related to the esterifying acids of pyrrolizidine alkaloids, from the costal fringes of male ithomiinae. Journal of Chemical Ecology, 2, 263-270.

Edwards, A. (1972). Likelihood. Cambridge, Cambridge University Press.

Elias, M., Hill, R.I., Willmott, K.R., Dasmahapatra, K.K., Brower, A.V.Z., Mallet, J. \& Jiggins, C.D. (2007). Limited performance of DNA barcoding in a diverse community of tropical butterflies. Proceedings of the Royal Society of London. Series B: Biological Sciences, 274, 2881-2889.

Evanno, G., Regnaut, S. \& Goudet, J. (2005). Detecting the number of clusters of individuals using the software STRUCTURE: a simulation study. Molecular Ecology, 14, 2611-2620.

Hart, N. (2004). Microspectrophotometry of visual pigments and oil droplets in a marine bird, the wedge-tailed shearwater Puffinus pacificus: topographic variations in photoreceptor spectral characteristics. Journal of Experimental Biology, 207, 1229-1240.

Hart, N., Partridge, J., Cuthill, I. \& Bennett, A. (2000). Visual pigments, oil droplets, ocular media and cone photoreceptor distribution in two species of passerine bird: the blue tit (Parus caeruleus L.) and the blackbird (Turdus merula L.). Journal of Comparative Physiology, A, 186, 375-387.

Iriel, A. \& Lagorio, M. (2010). Implications of reflectance and fluorescence of Rhododendron indicum flowers in biosignaling. Photochemical and Photobiological Sciences, 9, 342-348.

Jiang, Y., Bolnick, D. \& Kirkpatrick, M. (2013). Assortative mating in animals. American Naturalist, 181, E125-E138. 
563 Jiggins, C., Mallarino, R., Willmott, K. \& Bermingham, E. (2006). The phylogenetic pattern of 564 speciation and wing pattern change in Neotropical Ithomia butterflies (Lepidoptera: Nymphalidae). Evolution, 60, 1454-1466.

566 Jiggins, C., Naisbit, R., Coe, R. \& Mallet, J. (2001). Reproductive isolation caused by colour 567 pattern mimicry. Nature, 411, 302-305.

568 Kopp, M., Servedio, M., Mendelson, T., Safran, R., Rodríguez, M., Hauber, M., Scordato, E., 569 Symes, L., Balakrishnan, C., Zonana, D. \& Sander Van Doorn, G. (2018). Mechanisms of assortative mating in speciation with gene flow: connecting theory and empirical research.

572 Lamas, G. (2004). Atlas of Neotropical Lepidoptera. Checklist: Part 4A. Hesperioidea$573 \quad$ Papilionoidea. Gainsville, Scientific Publishers.

574 Le Poul, Y., Whibley, A., Chouteau, M., Prunier, F., Llaurens, V. \& Joron, M. (2014). Evolution 575 of dominance mechanisms at a butterfly mimicry supergene. Nature communications, $\mathbf{5}$, 576 DOI: $10.1038 /$ ncomms6644.

577 Llaurens, V., Joron, M. \& Théry, M. (2014). Cryptic differences in colour among Müllerian 578 mimics: how can the visual capacities of predators and prey shape the evolution of wing 579 colours? Evolutionary Biology, 27, 531-540.

580 Maan, M. \& Seehausen, O. (2012). Magic cues versus magic preferences in speciation. 581 Evolutionary Ecology Research, 14, 779-785.

582 Mallet, J. \& Barton, N. (1989). Strong natural selection in a warning-color hybrid zone. Evolution, 583 43, 421-431.

584 Martinez Arbizu, P. (2017). pairwiseAdonis: Pairwise multilevel comparison using adonis. $R$ 585 package version 0.0.1. 
McClure, M., Chouteau, M., Bernard, A. \& Elias, M. (2014). The development and characterization of polymorphic microsatellite loci for the genus Melinaea (Nymphalidae, Ithomiini). Conservation Genetics Resources, 6,(4), 891-893.

McClure, M., Dutrillaux, B., Dutrillaux, A.-M., Lukhtanov, V. \& Elias, M. (2018). Heterozygosity and chain multivalents during meiosis illustrate ongoing evolution as a result of multiple holokinetic chromosome fusions in the genus Melinaea (Lepidoptera, Nymphalidae). Cytogenetic and Genome Research, 153, 213-222.

McClure, M., Mahrouche, L., Houssin, C., Monllor, M., Le Poul, Y., Frérot, B., Furtos, A. \& Elias, M. (2019). Data from: Does divergent selection predict the evolution of mate preference and reproductive isolation in the tropical butterfly genus Melinaea (Nymphalidae: Ithomiini)? Dryad Digital Repository. https://doi.org/10.5061/dryad.008b59c.

McClure, M. \& Elias, M. (2016). Unravelling the role of host plant expansion in the diversification of a Neotropical butterfly genus. BMC Evolutionary Biology, 16, 128-134.

McClure, M. \& Elias, M. (2017). Ecology, life history, and genetic differentiation in Neotropical Melinaea (Nymphalidae: Ithomiini) butterflies from north-eastern Peru. Zoological Journal of the Linnean Society, 179, 110-124.

McCulloch, K., Osorio, D. \& Briscoe, A. (2016). Sexual dimorphism in the compound eye of Heliconius erato: a nymphalid butterfly with at least five spectral classes of photoreceptor. Journal of Experimental Biology, 219, 2377-2387.

McMillan, W., Jiggins, C. \& Mallet, J. (1997). What initiates speciation in passion-vine butterflies? Proceedings of the National Academy of Sciences of the United States of America, 94, 8628-8633. 
608

609

610

611

612

613

614

615

616

617

618

619

620

621

622

623

624

625

626

627

628

629

Merrill, R., Wallbank, R., Bull, V., Salazar, P., Mallet, J., Stevens, M. \& Jiggins, C. (2012). Disruptive ecological selection on a mating cue. Proceedings of the Royal Society of London B, 279, 4907-4913.

Müller, F. (1897). Ituna and Thyridia; a remarkable case of mimicry in butterflies. Transactions of the Entomological Society of London.

Naisbit, R.E., Jiggins, C.D. \& Mallet, J. (2001). Disruptive sexual selection against hybrids contributes to speciation between Heliconius cydno and H. melpomene. Proceedings of the Royal Society of London. Series B: Biological Sciences, 268, 1849-1854.

Oksanen, J., Blanchet, F., Kindt, R., Legendre, R., McGlinn, D., Minchin, P., O'Hara, R., Simpson, G., Solymos, P., Stevens, M., Szoecs, E. \& Wagner, H. (2016). Vegan: Community ecology package. $R$ package version 2.4-1.

Pritchard, J., Stevens, M. \& Donnelly, P. (2000). Inference of population structure using multilocus genotype data. Genetics, 155, 945-959.

Puebla, O., Bermingham, E., Guichard, F. \& Whiteman, E. (2007). Colour pattern as a single trait driving speciation in Hypoplectrus coral reef fiches? Proceedings of the Royal Society of London, Series B: Biological Sciences, 274, 1265-1271.

Raymond, M. \& Rousset, F. (1995). An exact test for population differentiation. Evolution, 49, $1280-1283$.

Reynolds, R. \& Fitzpatrick, B. (2007). Assortative mating in poison-dart frogs based on an ecologically important trait. Evolution, 61, 2253-2259.

Schulz, S., Beccaloni, G., Brown, K., Boppré, M., Freitas, A., Ockenfels, P. \& Trigo, J. (2004). Semiochemicals derived from pyrrolizidine alkaloids in male ithomiine butterflies 
(Lepidoptera: Nymphalidae: Ithomiinae). Biochemical Systematics and Ecology, 32, 699713.

Servedio, M. \& Boughman, J.W. (2017). The role of sexual selection in local adaptation and speciation. Annual Review of Ecology, Evolution and Systematics, 48, 85-109.

Servedio, M., Sander Van Doorn, G., Kopp, M., Frame, A. \& Nosil, P. (2011). Magic traits in speciation: 'magic' but not rare? Trends in Ecology \& Evolution, 26, 389-397.

Stalleicken, J., Labhart, T. \& Mouritsen, H. (2006). Physiological characterization of the compound eye in monarch butterflies with focus on the dorsal rim area. Journal of Comparative Physiology, A, 192, 321-331.

Stavenga, D. (2010). On visual pigment templates and the spectral shape of invertebrate rhodopsins and metarhodopsins. Journal of Comparative Physiology, A, 196, 869-878.

Twomey, E., Vestergaard, J., Venegas, P. \& Summers, K. (2016). Mimetic divergence and the speciation continuum in the the mimic poison frog Ranitomeya imitator. American Naturalist, 187, 205-224.

Vorobyev, M., Osorio, D., Bennett, A., Marshall, N. \& Cuthill, I. (1998). Tetrachromacy, oil droplets and bird plumage colours. Journal of Comparative Physiology, A, 183, 621-633.

Whinnett, A., Zimmermann, M., Willmott, K.R., Herrera, N., Mallarino, R., Simpson, F., Joron, M., Lamas, G. \& Mallet, J. (2005). Strikingly variable divergence times inferred across an Amazonian butterfly 'suture zone'. Proceedings of the Royal Society of London. Series B: Biological Sciences, 272,(2525-2533).

Willmott, K.R. \& Freitas, A. (2006). Higher-level phylogeny of the Ithomiinae (Lepidoptera: Nymphalidae): classification, patterns of larval hostplant colonization and diversification. Cladistics, 22, 297-368. 
653 Yukilevich, R. (2012). Asymmetrical patterns of speciation uniquely support reinforcement in 654 Drosophila. Evolution, 66, 1430-1446.

655

656 


\section{List of Figures}

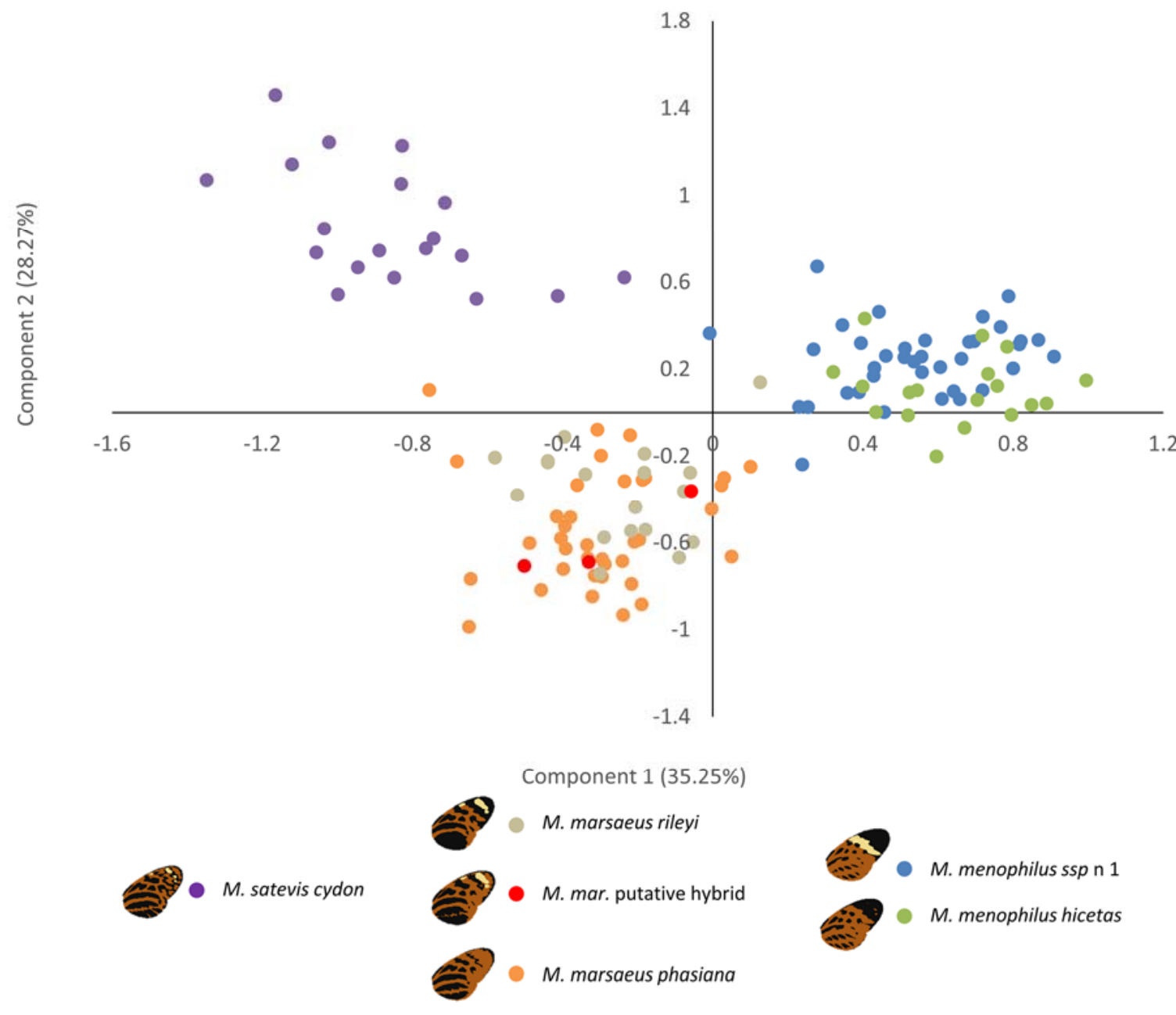

658

659 Figure 1: Factorial correspondence analysis for five Melinaea taxa and putative hybrids between

660 subspecies of M. marsaeus on 12 microsatellite loci computed using the program GENETIX 


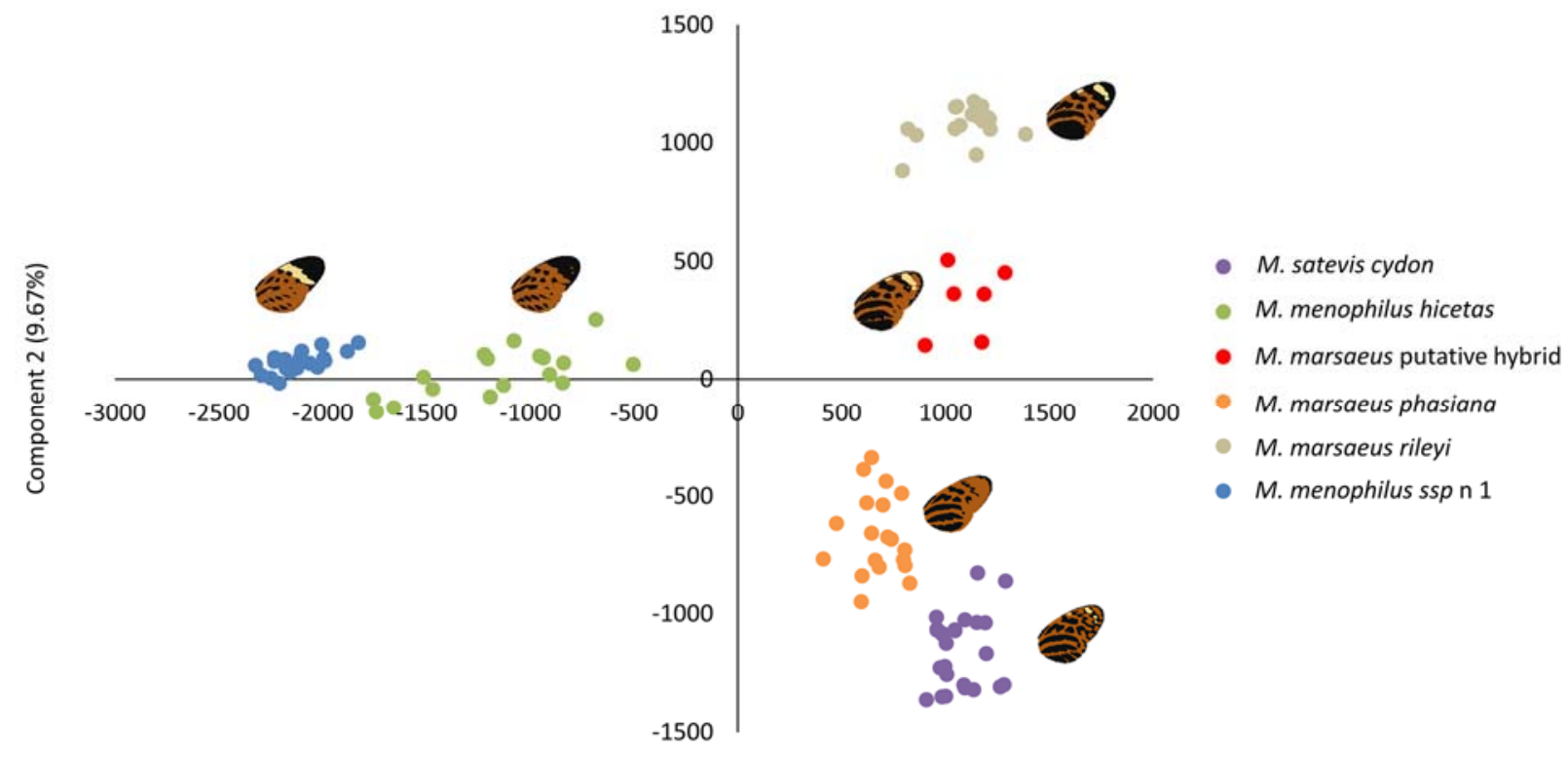

662

663 b

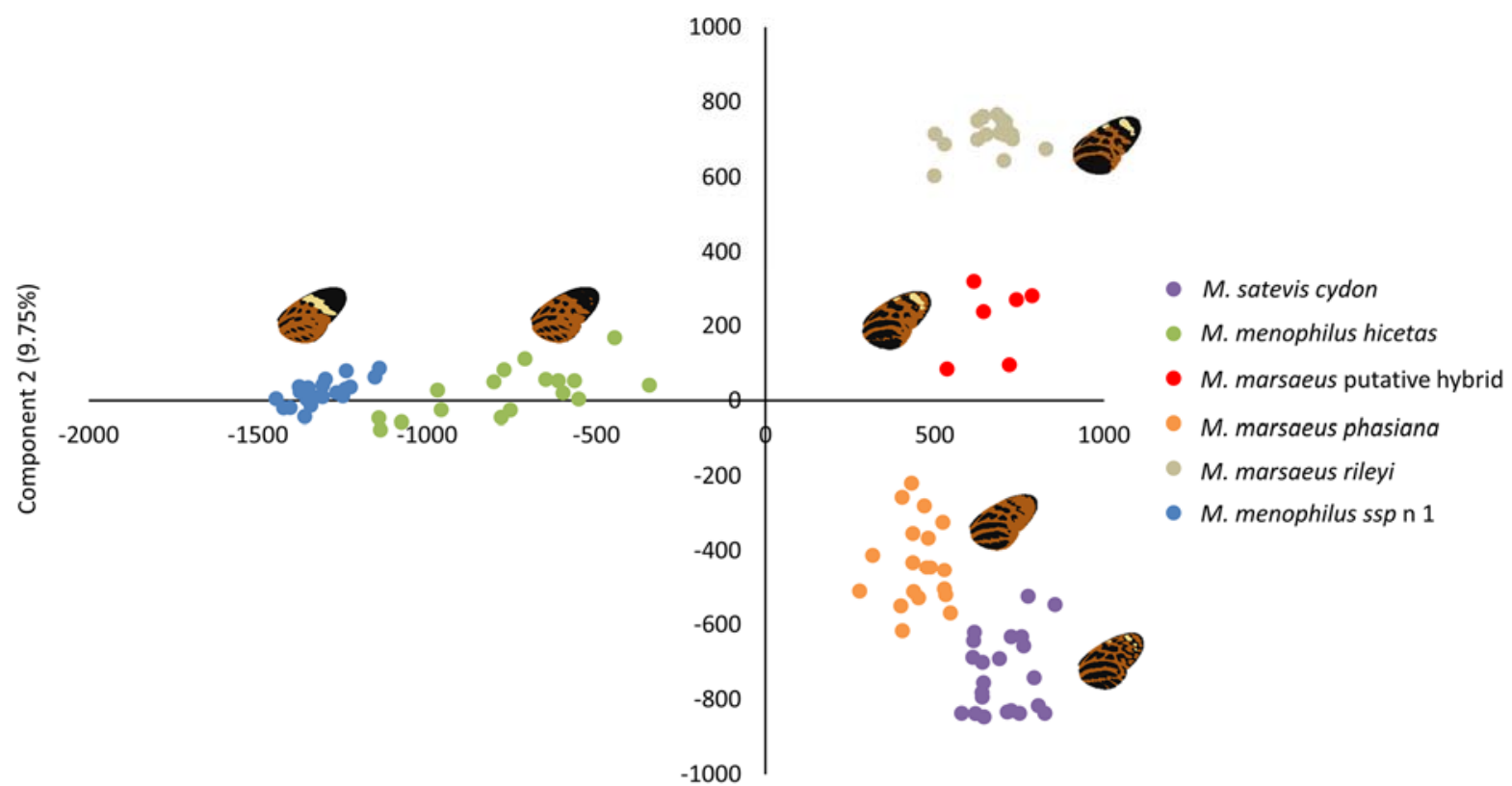

Component 1 (29.38\%) 
665 Figure 2: Principal component analysis showing the variation in the colour pattern of five 666 Melinaea taxa and putative hybrids between subspecies of M. marsaeus as quantified by Colour 667 Pattern Modelling and modelled on a) butterfly vision and b) UVS bird vision

668

669

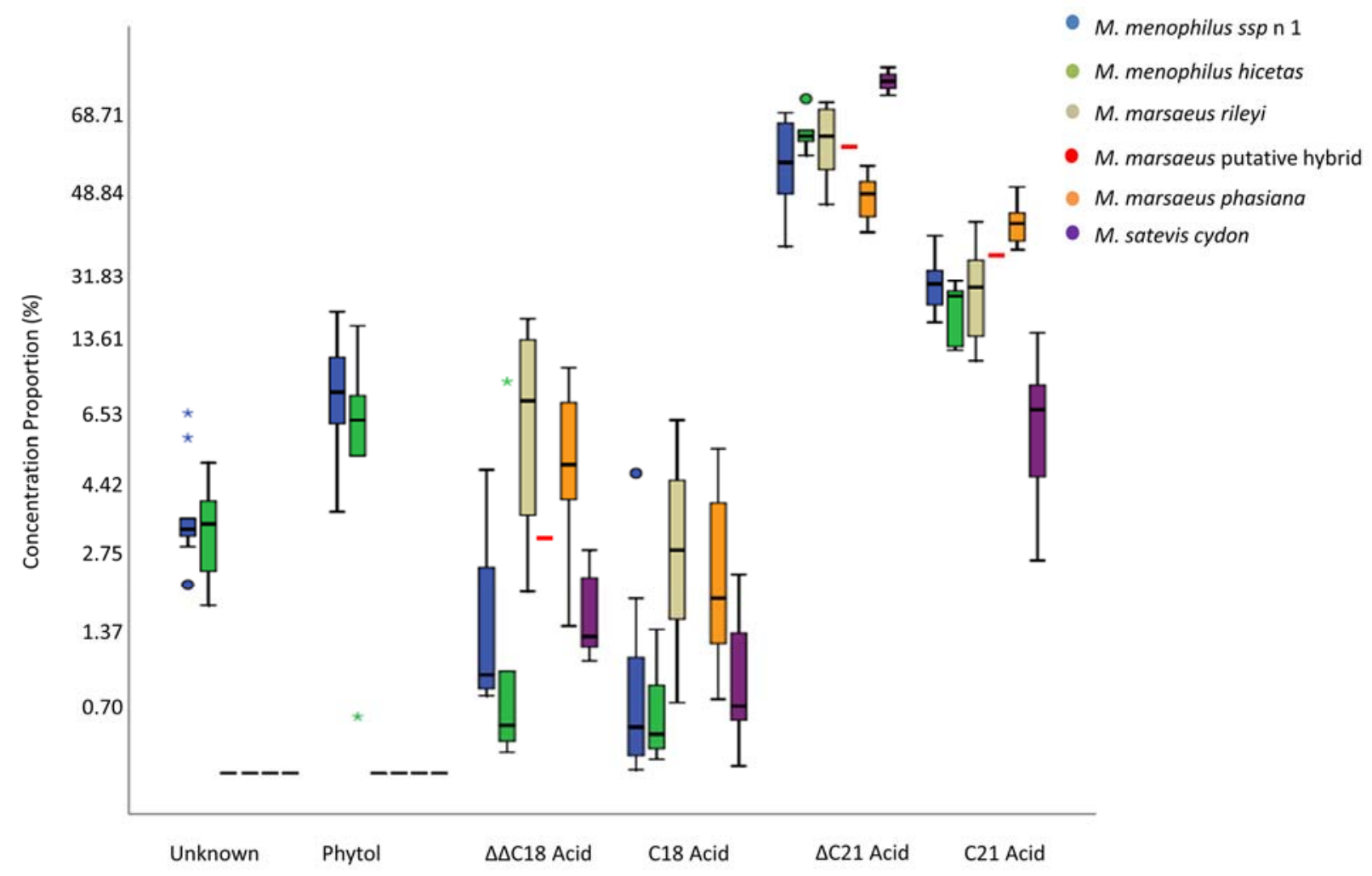

670 Figure 3: Proportion of the different compounds present in the chemical profile of five Melinaea

671 taxa and one putative hybrid between subspecies of $M$. marsaeus obtained by GC-MS

672 


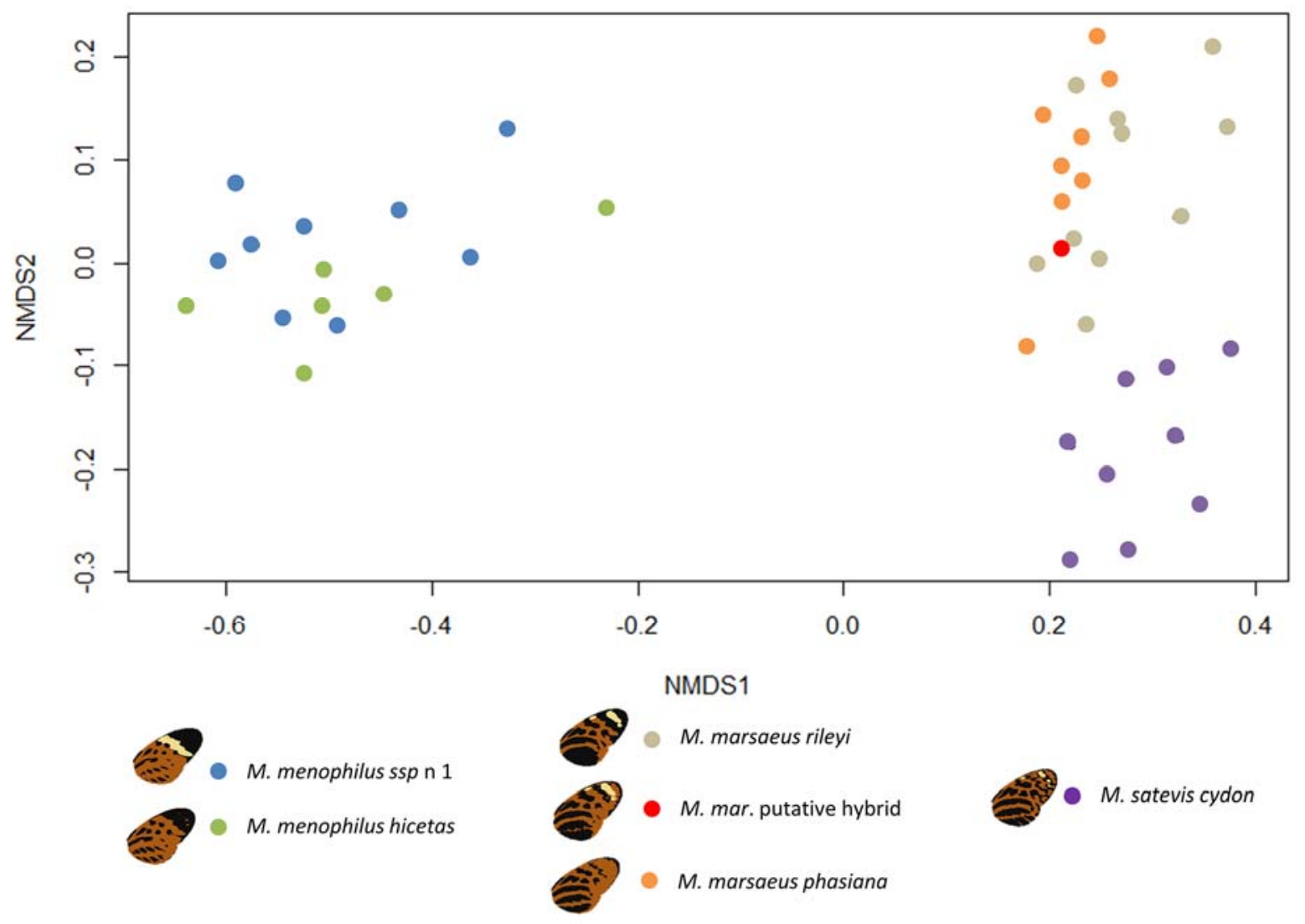

673

674 Figure 4: NMDS ordination plot based on Bray-Curtis distances calculated on the chemical profile 675 obtained by GC-MS of five Melinaea taxa and one putative hybrid between subspecies of $M$.

676 marsaeus

677

678 
679 Table 1. The number of individuals of each Melinaea taxon used to measure genetic

680 differentiation, pheromone characterization and colour pattern quantification

\begin{tabular}{l|ccc}
\multicolumn{1}{c}{} & $\begin{array}{c}\text { Genetic } \\
\text { differentiation }\end{array}$ & $\begin{array}{c}\text { Pheromone } \\
\text { characterization }\end{array}$ & $\begin{array}{c}\text { Colour } \\
\text { pattern } \\
\text { quantification }\end{array}$ \\
\cline { 2 - 4 } M. menophilus ssp. nov. 1 & 37 & 9 & 20 \\
M. menophilus hicetas & 18 & 6 & 17 \\
M. marsaeus rileyi & 18 & 10 & 20 \\
M. marsaeus putative hybrid & 3 & 1 & 6 \\
M. marsaeus phasiana & 37 & 8 & 19 \\
M. satevis cydon & 19 & 9 & 22
\end{tabular}


Table 2. Observed mating probabilities within and between different Melinaea taxa and the resulting best fitting model for each (i.e.

685 whether different taxa mate less frequently than those of the same taxon, or if all crosses are either equal or all significantly different

686 from one another). Different lower-case letters indicate significant differences of $p<0.05$ for each cross, based on the best fitting model

687 obtained

\begin{tabular}{|c|c|c|c|c|}
\hline No-choice mating experiments & $\begin{array}{c}\text { Number of } \\
\text { trials }\end{array}$ & $\begin{array}{c}\text { Number of } \\
\text { mating }\end{array}$ & $\begin{array}{c}\text { Mating } \\
\text { probability }\end{array}$ & $\begin{array}{c}\text { Best fitting } \\
\text { model }\end{array}$ \\
\hline M. menophilus ssp. nov. 1 x M. menophilus ssp. nov. 1 & 12 & 9 & $0.75^{\mathrm{a}}$ & $\mathrm{P}_{i i}=\mathrm{P}_{j j}=\mathrm{P}_{i j}=\mathrm{P}_{j i}$ \\
\hline M. menophilus ssp. nov. 1 x M. menophilus hicetas & 12 & 8 & $0.67^{\mathrm{a}}$ & \\
\hline M. menophilus hicetas $x$ M. menophilus hicetas & 12 & 7 & $0.58^{\mathrm{a}}$ & \\
\hline M. marsaeus rileyi $x$ M. marsaeus rileyi & 12 & 8 & $0.67^{\mathrm{a}}$ & $\mathrm{P}_{i i}=\mathrm{P}_{j j} \neq \mathrm{P}_{i j}=\mathrm{P}_{j i}$ \\
\hline M. marsaeus rileyi $x$ M. marsaeus phasiana & 12 & 0 & $0^{\mathrm{b}}$ & \\
\hline M. marsaeus phasiana x M. marsaeus phasiana & 12 & 6 & $0.5^{\mathrm{a}}$ & \\
\hline M. marsaeus $x$ M. marsaeus & 24 & 14 & $0.58^{\mathrm{a}}$ & $\mathrm{P}_{i i} \neq \mathrm{P}_{j j} \neq \mathrm{P}_{i j}=\mathrm{P}_{j i}$ \\
\hline M. marsaeus $x$ M. satevis cydon & 12 & 0 & $0^{\mathrm{b}}$ & \\
\hline M. satevis cydon $x$ M. satevis cydon & 12 & 11 & $0.92^{\mathrm{c}}$ & \\
\hline
\end{tabular}


690 Table 3. Measures of genetic differentiation (Fst), colour pattern differentiation as perceived by butterflies and birds (Euclidean

691 distances between group centroids), pheromone differentiation and the index of premating isolation (where $0=$ no mating isolation,

$6921=$ complete mating isolation) for different pairs of Melinaea taxa. For clarity and ease of comparison, a relative value ranging from 0 to

693 1, calculated as the absolute Euclidean distance value divided by the maximum value observed in the dataset, is included in brackets for

694 colour pattern and pheromones.

\section{Pairs of taxa}

M. menophilus ssp. nov. 1 \& M. men. hicetas

M. marsaeus phasiana \& M. mar. rileyi

M. marsaeus phasiana \& M. mar. putative hybrid

M. marsaeus rileyi \& M. mar. putative hybrid

M. satevis cydon \& M. mar. phasiana

M. satevis cydon \& M. mar. rileyi

M. satevis cydon \& M. mar. putative hybrid 695

696
Fst

0.013

0.006

0.04

0.02

\section{Colour pattern distances (butterflies)}

$1.47 \times 10^{3}(0.63)$

$2.19 \times 10^{3}(0.94)$

$1.38 \times 10^{3}(0.59)$

$1.19 \times 10^{3}(0.51)$

$1.83 \times 10^{3}(0.78)$

$2.33 \times 10^{3}(1.00)$

$1.85 \times 10^{3}(0.79)$

\section{Colour pattern} distances (birds)

$0.85 \times 10^{3}(0.57)$

$1.42 \times 10^{3}(0.94)$

$0.91 \times 10^{3}(0.60)$

$0.79 \times 10^{3}(0.52)$

$1.20 \times 10^{3}(0.80)$

$1.51 \times 10^{3}(1.00)$

$1.20 \times 10^{3}(0.80)$
Index of

Pheromone premating distances isolation

$10.65(0.20) \quad 0$

$22.46(0.42) \quad 1$

$53.24(1.00)$

$32.04(0.60)$ 
697 Table 4. Compounds identified in extracts of male hair pencils (i.e. androconial scales) of different 698 Melinaea taxa (* indicates identification through NIST)

699

\begin{tabular}{cll}
$\begin{array}{c}\text { Retention } \\
\text { index }\end{array}$ & $\begin{array}{l}\text { Compound } \\
\text { identification }\end{array}$ & Melinaea taxa \\
\hline 1202.68 & Unknown & M. menophilus \\
2114.63 & Phytol* $^{*}$ & M. menophilus \\
2438.06 & $\Delta \Delta$ C18 acid & all taxa \\
2454.92 & Fatty acid ester & all taxa \\
2638.32 & $\Delta$ C21 acid & all taxa \\
2661.19 & C21 acid & all taxa
\end{tabular}

700

701 


\section{Supplementary Information \& Figures}

703 Table S1. Expected frequency of M. marsaeus hybrids based on Hardy-Weinberg equilibrium.

704 Shown are the results for the Pearson's $\chi^{2}$ test comparing the expected and the observed

705 frequencies of putative hybrids for the entire distribution (i.e. all localities were pooled) and for

706 the contact/hybrid zone specifically

\begin{tabular}{lccccc} 
& $\operatorname{Exp}(\mathbf{M}$. mar. phasiana) & $\operatorname{Exp}($ M. mar. hybrid) & $\operatorname{Exp}($ M. mar. rileyi) & $\chi 2$ (df=1) & $p$ \\
\cline { 2 - 6 } Contact zone & 2.34 & 10.31 & 11.34 & 12.07 & $p<0.001$ \\
Total distribution & 23.09 & 83.83 & 76.09 & 149.74 & $p<0.001$
\end{tabular}

707

708

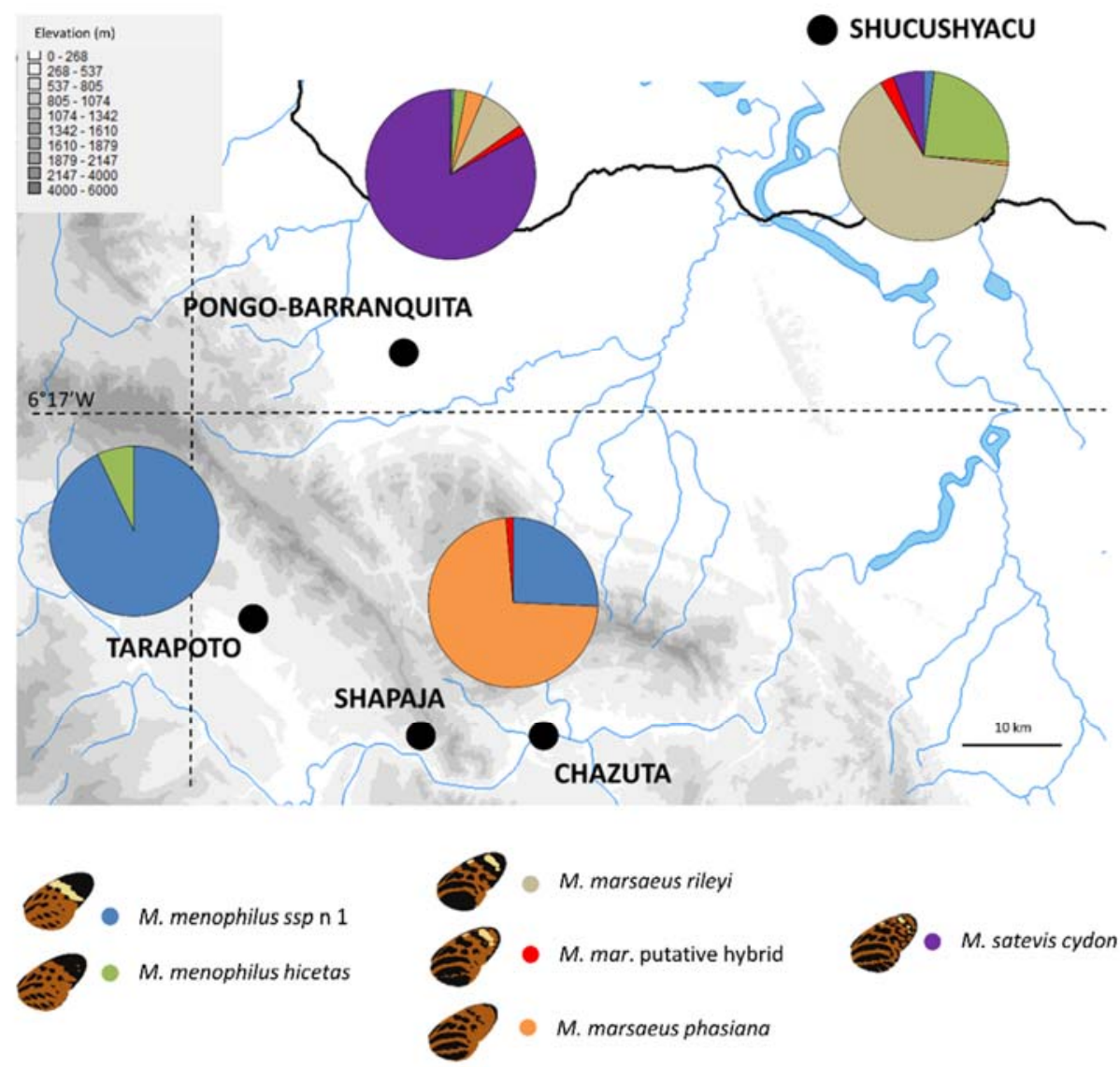

710 Figure S1: Distribution of five different Melinaea taxa and putative hybrids between subspecies of M. marsaeus in north-eastern Peru 


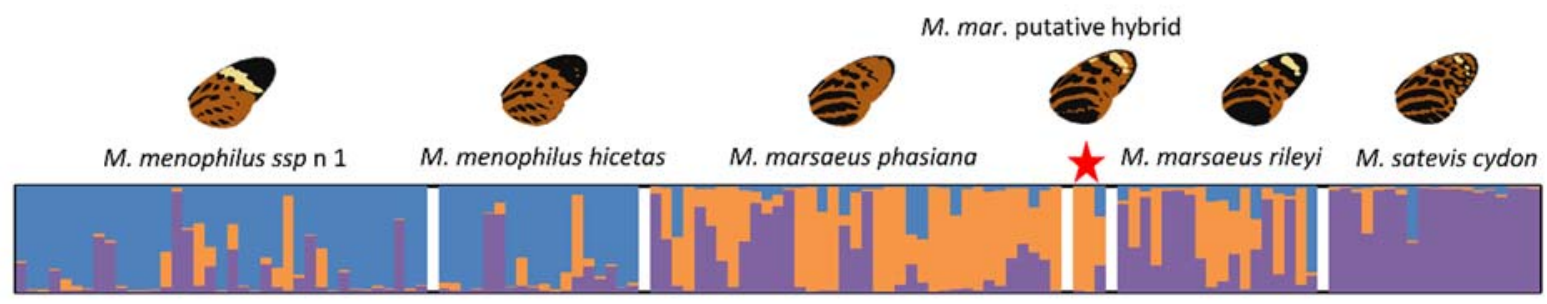

712

713 Figure S2: STRUCTURE plot based on 12 polymorphic microsatellite loci for 5 different

714 Melinaea taxa and putative hybrids between subspecies of M. marsaeus (indicated with a red star).

715 Bar colours represent posterior possibilities of assignment to inferred genotypic group

716

717

a

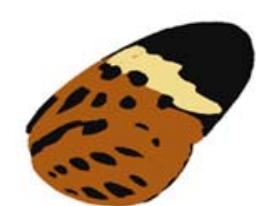

M. menophilus ssp n 1

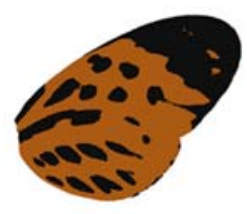

M. men. hicetas

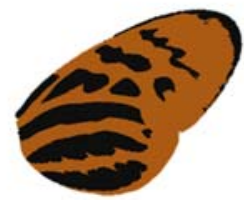

M. marsaeus phasiana

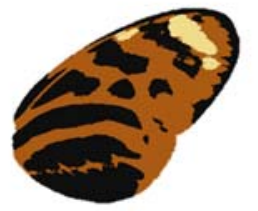

M. mar. putative hybrid

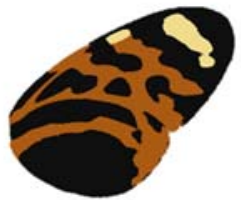

M. mar. rileyi

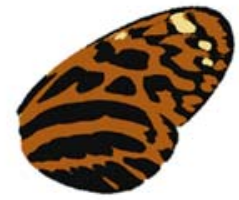

M. satevis cydon

b

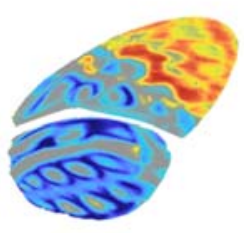

Black

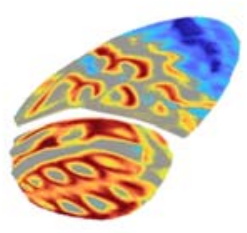

Orange

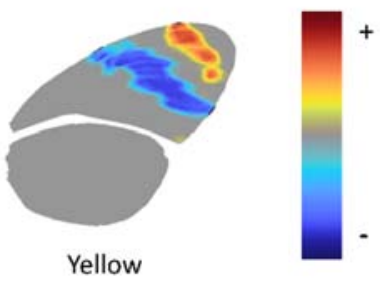

Figure S3: a) Average wing colour patterns for the five Melinaea taxa and putative hybrids between subspecies of $M$. marsaeus and b) the heatmaps generated to visualize the degree of

721 variation (from blue to red) across taxa for each of the three colours (black, orange and yellow)

722 across the wing 


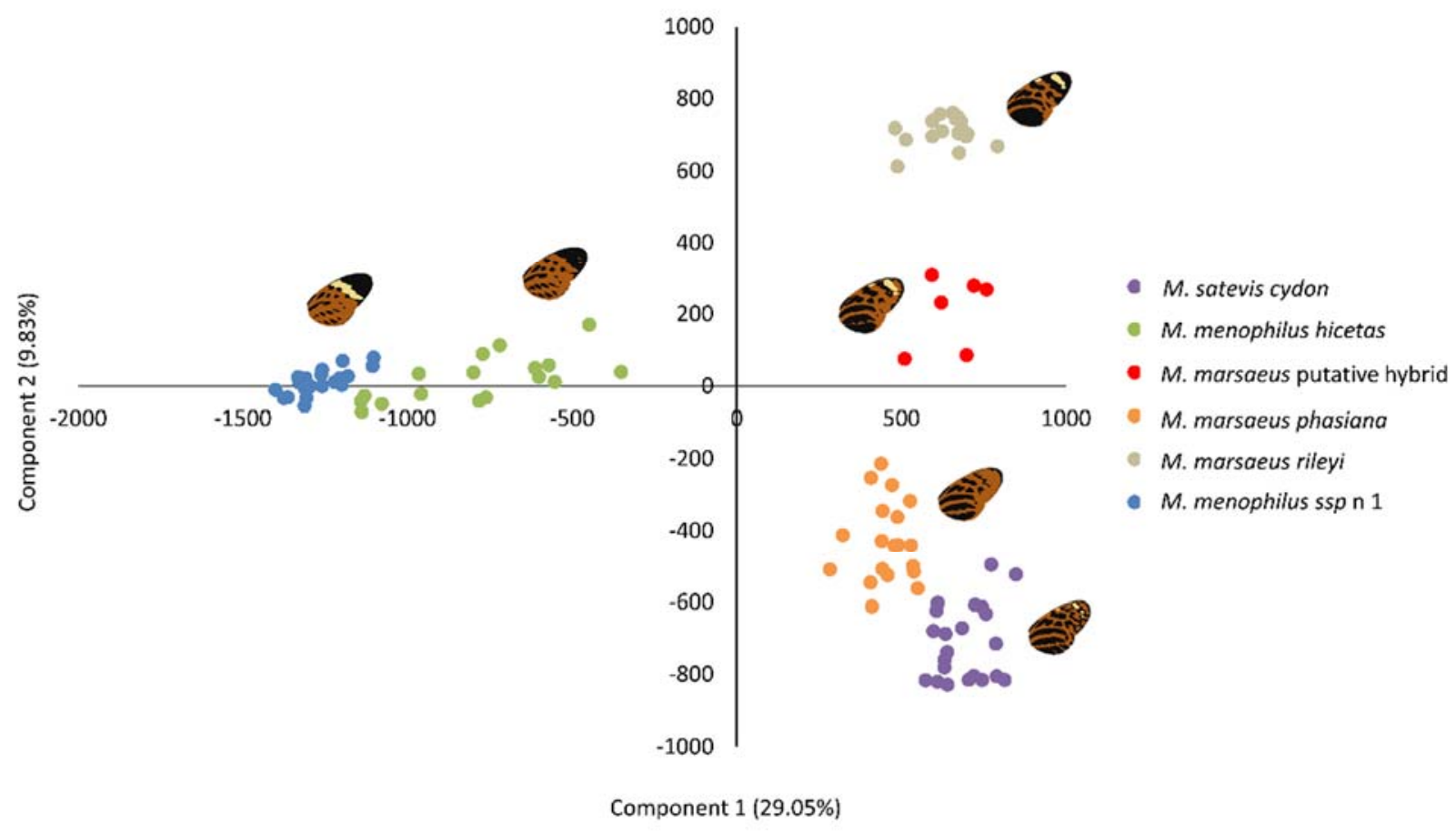

Figure S4: Principal component analysis showing the variation in the colour pattern of five Melinaea taxa and putative hybrids between subspecies of M. marsaeus as quantified by Colour

727 Pattern Modelling and modelled on VS bird vision

\section{Supplementary Files Available Online}

732 ESM File. Vision modelling of four effective photoreceptors of the monarch butterfly, Danaus

733 plexippus, based on sensitivity peaks reported by Stalleicke et al. (2006) and Blackiston et al.

734 (2011), and of a dark orange filter reported by Blackiston et al. (2011) and extrapolated from the spectrum presented for Heliconius erato in McCulloch et al. (2016). Relative proportions of

736 photoreceptors are 1:1:3:3. 